\title{
Vitamin D deficiency and TB disease phenotype
}

\author{
Manish Pareek, ${ }^{1,2,3,4}$ John Innes, ${ }^{5}$ Saranya Sridhar, ${ }^{2}$ Lisa Grass, ${ }^{2}$ David Connell, ${ }^{2}$ \\ Gerrit Woltmann, ${ }^{6}$ Martin Wiselka, ${ }^{4}$ Adrian R Martineau, ${ }^{7}$ Onn Min Kon, ${ }^{8}$ \\ Martin Dedicoat, ${ }^{5}$ Ajit Lalvani ${ }^{2,8}$
}

\begin{abstract}
- Additional material is published online only. To view please visit the journal online (http://dx.doi.org/10.1136/ thoraxjnl-2014-206617).

For numbered affiliations see end of article.

\section{Correspondence to} Professor Ajit Lalvani,
\end{abstract} a.lalvani@imperial.ac.uk

Received 1 December 2014 Revised 6 March 2015 Accepted 14 April 2015 Published Online First 23 September 2015
CrossMark

\footnotetext{
To cite: Pareek M, Innes J, Sridhar $\mathrm{S}$, et al. Thorax 2015;70:1171-1180.
}

\section{ABSTRACT \\ Background Extrapulmonary TB is increasingly common, yet the determinants of the wide clinical spectrum of TB are poorly understood.}

Methods We examined surveillance data (Birmingham, UK: 1980-2009 and USA Centers for Disease Control: 1993-2008) to identify demographic factors associated with extrapulmonary TB. We then directly tested association of these factors and serum 25hydroxycholecalciferol $(25(\mathrm{OH}) \mathrm{D})$ concentration with extrapulmonary TB by multivariable analysis in a separate UK cohort.

Results Data were available for 10152 and 277013 TB cases for Birmingham and US, respectively. Local-born individuals of white ethnicity had a lower proportion of extrapulmonary disease when compared with local-born non-whites $(p<0.0001)$; both groups had a lower proportion of extrapulmonary disease when compared with foreign-born non-whites $(p<0.0001)$. In a separate UK cohort $(n=462)$, individuals with extrapulmonary TB had lower mean serum 25(OH)D concentration than those with pulmonary TB (11.4 vs $15.2 \mathrm{nmol} / \mathrm{L}$, respectively, $p=0.0001)$. On multivariable analysis, vitamin $\mathrm{D}$ deficiency was strongly associated with extrapulmonary TB independently of ethnicity, gender and other factors. Doubling in serum $25(\mathrm{OH}) \mathrm{D}$ concentration conferred substantially reduced risk of extrapulmonary disease (OR 0.55, 95\% Cl 0.41 to 0.73).

Conclusions We identify vitamin $D$ deficiency as a probable risk factor for extrapulmonary dissemination in $\mathrm{TB}$, which may account for the associations of darkskinned ethnicity and female gender with extrapulmonary disease. Our findings implicate vitamin D status in Mycobacterium tuberculosis containment in vivo and, given the high prevalence of deficiency, may inform development of novel TB prevention strategies.

\section{INTRODUCTION}

Although TB presents as a broad spectrum of clinical phenotypes, clinically categorised as pulmonary and extrapulmonary disease, little is known about the determinants of this clinical spectrum. Although pulmonary TB is the commonest presentation, extrapulmonary TB accounts for a large and growing proportion. ${ }^{12}$

The most important known risk factors for extrapulmonary TB are untreated HIV infection, iatrogenic immunosuppression (especially anti-tumour necrosis factor- $\alpha$ therapy) and infancy. ${ }^{3}{ }^{4}$ This association with impaired cellular immunity suggests that extrapulmonary disease in immunocompetent

\section{Key messages}

What is the key question?

- What are the factors that result in extrapulmonary TB phenotype?

What is the bottom line?

- Vitamin D deficiency is strongly and independently associated with extrapulmonary TB at the time of TB diagnosis.

\section{Why read on?}

- Our data provide the first evidence for vitamin $D$ determining TB disease phenotype and help to explain the longstanding yet unexplained association of extrapulmonary TB with ethnicity and geographical origin.

adults may reflect a more subtle impairment of host responses that mediate bacterial containment in vivo. Genetic factors associated with extrapulmonary TB include polymorphisms in vitamin D receptor, $^{5}{ }^{6}$ interleukin-1 $\beta,{ }^{6} 7$ Toll-like receptor 2 $(\mathrm{TLR} 2 / 1)^{6}$ and the P2X7 gene, suggesting a role for innate immunity in containment versus extrapulmonary dissemination. ${ }^{8}$ Pathogen-related factors may also influence disease phenotype and certain mycobacterial lineages are associated with extrapulmonary $\mathrm{TB},{ }^{9}$ although these associations have been inconsistent. $^{9} 10$

Recent epidemiological studies in high-income lowburden Northern Hemisphere countries (including the USA, UK and Germany) have revealed a disproportionate incidence of extrapulmonary $\mathrm{TB}$ in ethnic minority populations from high-burden regions. ${ }^{1} 211$ Indeed, ethnicity appears to be strongly associated with extrapulmonary TB independently of mycobacterial lineage. ${ }^{12}$ We postulated that a detailed international epidemiological analysis of clinical disease phenotype encompassing diverse ethnic groups and immigrants from high-burden to low-burden regions might delineate hitherto unrecognised host or environmental factors that influence extrapulmonary dissemination and clinical disease spectrum.

\section{METHODS}

\section{Study design and description of data sources}

We used routine anonymous TB surveillance data prospectively notified in two independent high- 
income settings: Birmingham/Solihull, UK and US Centers for Disease Control (CDC).

Birmingham/Solihull has a population of 1.22 million $^{13}$ and between 2007 and 2009 (for Birmingham and Solihull, respectively) the 3-year average TB notifications were 441 and 12, while incidence was 42 and 6 (per 100000 population per year), respectively. ${ }^{14}$ All TB cases are recorded in a centralised chest clinic database allowing ascertainment of all notified cases since 1980 .

To confirm that patterns found during the study were not purely UK specific, we analysed data from an independent US dataset-the publicly-available US TB surveillance dataset (Online Tuberculosis Information System-OTIS; http://wonder. cdc.gov/tb.html) which holds aggregate data (individual level information is not publicly available) for all verified cases of active TB in the USA from 1993 to $2008 .^{15}$

\section{Study populations and data collection}

We included all cases of active TB diagnosed between 1 January 1980-31 December 2009 (Birmingham/Solihull) and 1 January 1993-31 December 2008 (US CDC) with complete data on age, sex, country of birth (whether local-born or foreign-born), ethnicity and site of disease; patients with missing information for one or more of these variables were excluded from analysis. Further information gathered from the datasets is presented in the online supplementary methods (SI appendix).

\section{Measurement of 25(OH)D in a separate UK TB cohort}

We included all consecutively diagnosed cases of active TB recruited between 1 November 2007 and 30 June 2011 (London) and 1 January 2010 and 10 July 2012 (Leicester; with complete demographic and clinical data). We included those patients where, depending on the treating physician's practice, a serum 25(OH)D sample had been drawn up to 90 days prior to diagnosis or within 30 days of treatment initiation.

\section{Definitions of patterns of tuberculous disease}

Active TB cases were defined by the major sites of disease into three distinct clinical patterns: pulmonary-only (only lung parenchyma involved), extrapulmonary-only (only one or more extrapulmonary site(s) involved) and both pulmonary and extrapulmonary (pulmonary disease and one or more extrapulmonary sites involved concurrently). Further details of the definitions of different patterns of disease are outlined in the online supplementary methods (SI appendix).

\section{Data analysis}

Data analysis was conducted in several steps. Continuous data were summarised with median and IQR and compared using the non-parametric Mann-Whitney $U$ test. Categorical responses were expressed as a percentage and comparisons made using Pearson's $\chi^{2}$ test (or Fisher's exact test if appropriate).

For the Birmingham and CDC datasets, we assessed temporal trends in extrapulmonary TB diagnosis (using $\chi^{2}$ test for trend) and compared the numbers (and proportion) of cases of each disease type stratified by local/foreign-birth and white/non-white ethnicity (using Fisher's exact test). Univariable analysis of factors associated with extrapulmonary TB only was assessed using logistical regression and reported as crude ORs and 95\% CIs. To calculate adjusted OR (and 95\% CI), we mutually adjusted for year, and season, of notification, age, gender, ethnicity, country of birth, time since arrival and HIV status (see online SI appendix for details of regression modelling).
For the London and Leicester datasets, we compared individuals with pulmonary and extrapulmonary disease using a one-way analysis of variance (on the log-transformed concentrations) with Bonferroni correction, if appropriate. The proportions of subjects who were severely vitamin D deficient (serum $25(\mathrm{OH}) \mathrm{D}<20 \mathrm{nmol} / \mathrm{L})$ were compared between groups using Fisher's exact test. We further assessed the factors associated with extrapulmonary $\mathrm{TB}$ in this dataset using logistical regression and reported results as ORs (with 95\% CIs). In the multivariable model we adjusted for centre (ie, London or Leicester), year, and season, of notification, age, gender, ethnic group, location of birth, time since arrival, HIV status and serum 25(OH)D concentration. Serum $25(\mathrm{OH}) \mathrm{D}$ was used as a continuous variable transformed by $\log _{2}$; each unit change in $\log _{2}$ serum 25 $(\mathrm{OH}) \mathrm{D}$ corresponds to a doubling in serum $25(\mathrm{OH}) \mathrm{D}$ on the original scale which thereby allows a more clinically relevant, and intuitive, interpretation of the ORs (see SI appendix for further details of logistical regression modelling).

Details of analytical methods are presented in the online supplementary methods (SI appendix). All analyses used STATA V.9.2 (StataCorp, Texas, USA). All tests were two tailed; $p$ values $\leq 0.05$ were considered significant.

\section{RESULTS}

\section{Description of cohorts}

Study population flow charts for the Birmingham and US CDC cohorts are outlined in the online supplementary figures S1A and $\mathrm{S} 1 \mathrm{~B}$, respectively.

Demographic characteristics of the Birmingham and US CDC cohort are set out in table 1. During the Birmingham study period (1980-2009), pulmonary-only disease decreased by $26.1 \%$, while extrapulmonary-only disease increased by $96.6 \%$ $(p<0.001)$; the proportion of cases that were exclusively extrapulmonary (compared with pulmonary-only) therefore increased from $31.6 \%$ to $52.9 \%$ ( $\chi^{2}$ for trend $\left.<0.001\right)$. During the CDC study period (between 1993-1996 and 2005-2008), overall TB notifications decreased by $43.2 \%$ but the decrease in pulmonary only cases $(46.5 \%)$ was greater than for extrapulmonary-only cases $(27.8 \%)$. Consequently, the proportion of cases that were exclusively extrapulmonary (as compared with pulmonary-only) increased from $17.8 \%$ to $22.6 \%\left(\chi^{2}\right.$ for trend $\left.\mathrm{p}<0.001\right)$.

\section{Relationship of clinical disease phenotype with foreign-birth and ethnicity}

Figure 1 outlines, for the Birmingham and US datasets, the proportion of cases that are pulmonary and extrapulmonary in different demographic groups.

Individuals of UK-born white ethnicity had a significantly lower proportion of extrapulmonary-only disease (18.1\%) as compared with individuals of UK-born non-white ethnicity $(34.3 \% ; \mathrm{p}<0.001)$ and both had a significantly lower proportion of extrapulmonary disease when compared with individuals of foreign-born non-white ethnicity (49.9\%; $\mathrm{p}<0.001$ for UK-born white and UK-born non-white). Similarly in the USA, US-born individuals of white ethnicity had a lower proportion of extrapulmonary-only disease (14.7\%) compared with individuals of US-born non-white ethnicity $(18.9 \%$; $<<0.001)$ and both groups had a lower proportion of extrapulmonary disease compared with foreign-born non-white cases $(24.1 \% ; \mathrm{p}<0.001$ for US-born white and US-born non-white).

\section{Other factors associated with extrapulmonary TB}

In the UK (table 2), multivariable analysis revealed that extrapulmonary $\mathrm{TB}$ was associated with increasing age up to 45 years 
Table 1 Demographic characteristics of individuals with active TB in the Birmingham and US CDC datasets

\begin{tabular}{|c|c|c|c|}
\hline Variable & Birmingham ( $n=10$ 152) & Variable & CDC USA $(n=277013)$ \\
\hline Age (median, IQR) & $35.0(23.0-55.0)$ & & \\
\hline Age categories & & Age categories & \\
\hline$<16$ & $1264(12.5 \%)$ & $<5$ & $10217(3.7 \%)$ \\
\hline $16-25$ & $1960(19.3 \%)$ & $5-14$ & $7123(2.6 \%)$ \\
\hline $26-35$ & $1990(19.6 \%)$ & $15-24$ & $25534(9.2 \%)$ \\
\hline $36-45$ & $1358(13.4 \%)$ & $25-44$ & $97349(35.1 \%)$ \\
\hline $46-55$ & $1101(10.6 \%)$ & $45-64$ & $76262(27.5 \%)$ \\
\hline over 55 & $2479(24.4 \%)$ & $>64$ & $60528(21.9 \%)$ \\
\hline Gender & & Gender & \\
\hline Female & $4902(48.3 \%)$ & Male & $173621(62.7 \%)$ \\
\hline Male & $5250(51.7 \%)$ & Female & $103392(37.3 \%)$ \\
\hline Ethnicity & & Ethnicity & \\
\hline White & $1991(19.6 \%)$ & American Indian or Alaska Native & $3532(1.3 \%)$ \\
\hline Indian Subcontinent & $6233(61.4 \%)$ & Asian or Pacific Islander & $56962(20.6 \%)$ \\
\hline Afro-Caribbean & $1484(14.6 \%)$ & Black or African American & $86697(31.3 \%)$ \\
\hline Oriental/other Asia & $220(2.2 \%)$ & Hispanic or Latino & $66934(24.2 \%)$ \\
\hline Other & $224(2.2 \%)$ & White, non-Hispanic & $62888(22.7 \%)$ \\
\hline Place of birth & & Place of birth & \\
\hline UK & $3612(35.6 \%)$ & USA & $153598(55.4 \%)$ \\
\hline Foreign-born & $6540(64.4 \%)$ & Foreign-born & $123415(44.6 \%)$ \\
\hline Time since entry to the UK (years)* & & Time since entry to the US (years) $\dagger$ & \\
\hline$<1$ & $331(5.7 \%)$ & $<1$ & $23897(23.7 \%)$ \\
\hline $1-5$ & $1943(33.3 \%)$ & $1-4$ & $24990(24.8 \%)$ \\
\hline $6-10$ & $818(14.0 \%)$ & $5-14$ & $27467(27.3 \%)$ \\
\hline$>10$ & $2740(47.0 \%)$ & $15+$ & $24280(24.1 \%)$ \\
\hline Employment status & & Employment status§ & \\
\hline Unemployed & $447(11.4 \%)$ & Unemployed & $144308(59.0 \%)$ \\
\hline Retired & $334(8.5 \%)$ & Employed & $100345(41.0 \%)$ \\
\hline Employed/housewife & $1670(42.4 \%)$ & & \\
\hline Student/child & $1486(37.7 \%)$ & & \\
\hline HIV statusף & & HIV status** & \\
\hline Negative & $171(88.6 \%)$ & Negative & $101606(77.9 \%)$ \\
\hline Positive & $22(11.4 \%)$ & Positive & $28836(22.1 \%)$ \\
\hline Previous TBt† & & Previous TB $\ddagger \ddagger$ & \\
\hline No & $4777(95.3 \%)$ & No & $260527(94.8 \%)$ \\
\hline Yes & $236(4.7 \%)$ & Yes & $14350(5.2 \%)$ \\
\hline Type of disease & & Type of disease & \\
\hline Pulmonary only & $5590(55.1 \%)$ & Pulmonary only & $203449(73.4 \%)$ \\
\hline Pulmonary and extrapulmonary & $763(7.5 \%)$ & Pulmonary and extrapulmonary & $21524(7.8 \%)$ \\
\hline Extrapulmonary only & $3799(37.4 \%)$ & Extrapulmonary only & $52040(18.8 \%)$ \\
\hline \multicolumn{4}{|l|}{ Site of extrapulmonary disease } \\
\hline Intrathoracic lymph node & $525(11.5 \%)$ & & \\
\hline Extrathoracic lymph node & $1907(41.8 \%)$ & & \\
\hline Bone and joint & $461(10.1 \%)$ & & \\
\hline Central nervous system & 169 (3.7\%) & & \\
\hline Pleura & $505(11.7 \%)$ & & \\
\hline Peritoneum & $108(2.4 \%)$ & & \\
\hline Genitourinary & $180(4.0 \%)$ & & \\
\hline Intestinal & $212(4.7 \%)$ & & \\
\hline Miliary & $198(4.3 \%)$ & & \\
\hline Pericardial & $51(1.1 \%)$ & & \\
\hline Soft tissue & $101(2.2 \%)$ & & \\
\hline Other & $538(11.8 \%)$ & & \\
\hline Culture positive§§ & & Culture positiveๆी & \\
\hline No & $5398(53.2 \%)$ & No & $56072(20.2 \%)$ \\
\hline Yes & $4754(46.8 \%)$ & Yes & 220941 (79.8\%) \\
\hline
\end{tabular}


Table 1 Continued

\begin{tabular}{|c|c|c|c|}
\hline Variable & Birmingham $(n=10$ 152) & Variable & CDC USA $(n=277013)$ \\
\hline Drug sensitivity*** & \multicolumn{3}{|c|}{ Drug sensitivity $+\dagger \dagger$} \\
\hline Fully sensitive & $1634(91.8 \%)$ & Not multidrug resistant & $206274(98.5 \%)$ \\
\hline Monodrug resistant & $116(6.5 \%)$ & Multidrug resistant & $3154(1.5 \%)$ \\
\hline \multirow[t]{4}{*}{ Multidrug resistant } & $30(1.7 \%)$ & & \\
\hline & \multicolumn{3}{|c|}{ 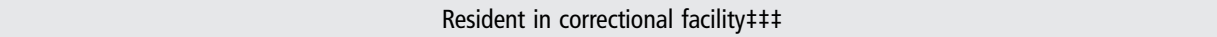 } \\
\hline & & No & $264422(96.3 \%)$ \\
\hline & & Yes & $10237(3.7 \%)$ \\
\hline \multicolumn{4}{|c|}{ 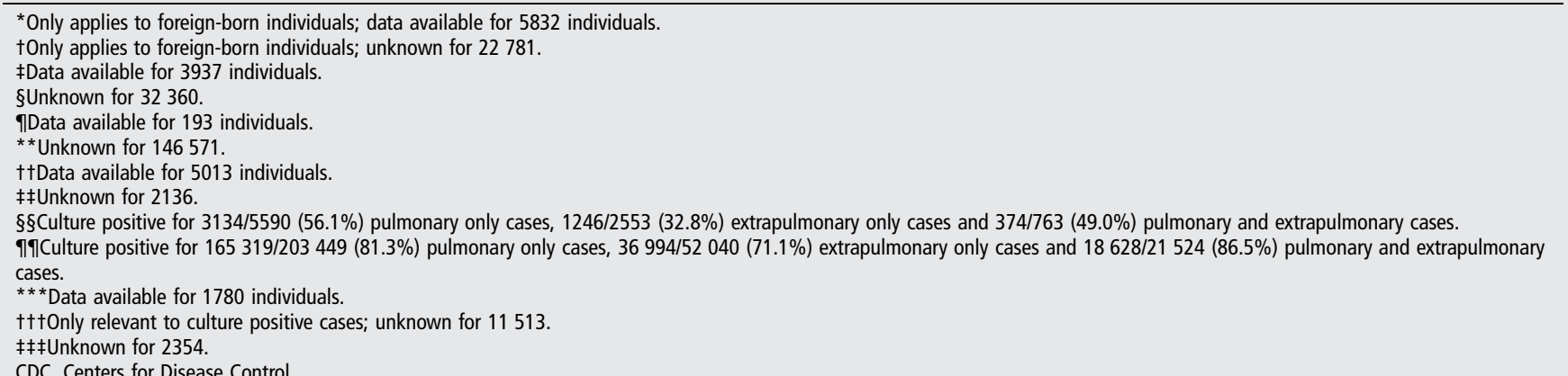 } \\
\hline
\end{tabular}

and female gender. In a sensitivity analysis of the UK data, including concurrent pulmonary and extrapulmonary case as extrapulmonary TB did not change the outcomes of the multivariable analysis (data not shown). Univariable analysis of the US population (see online supplementary table S1) revealed that extrapulmonary TB was associated with increasing age up to 45 years, female gender, employment status, HIV status (HIV-seropositivity), no history of $\mathrm{TB}$ and drug-sensitive disease.

In both the UK and the USA, as time between arrival and development of active TB increased, the proportion of foreignborn cases that were extrapulmonary doubled and then stabilised (from 24.9\% at $<1$ year to $51.8 \%$ at $>1$ year in Birmingham and from $13.3 \%$ at $<1$ year to $26.8 \%$ at $>1$ year in the USA; $\mathrm{p}<0.001$ for both Birmingham and the USA). Interestingly, foreign-born non-white individuals developing active TB within 12 months of arrival actually had a lower proportion of extrapulmonary TB $(24.9 \%$ in Birmingham and $13.3 \%$ in the USA) than local-born non-whites $(34.4 \%$ in Birmingham and $18.9 \%$ in the USA; $\mathrm{p}=0.001$ and $\mathrm{p}<0.001$ for Birmingham and US CDC, respectively).

\section{Association of serum 25(OH)D level with TB disease phenotype}

Given the associations we found between disease pattern and different demographic and ethnic groups, we postulated that vitamin $\mathrm{D}$ deficiency may be a key factor determining clinical phenotype. We therefore tested this hypothesis in a clinically precisely defined, ethnically diverse, cohort of 462 patients with TB from London and Leicester, UK (see online supplementary figure S2). Demographic details of the cohort are presented in the online supplementary table S2. Subjects included in the vitamin D cohort were younger and less likely to have HIV coinfection than those subjects excluded from the study due to lack of vitamin D data at diagnosis but were similar in all other respects (see online supplementary table $\mathrm{S} 2$ ).

Overall, mean serum $25(\mathrm{OH}) \mathrm{D}$ levels in the cohort were $12.6 \mathrm{nmol} / \mathrm{L}$ (95\% CI 11.8 to $13.5 \mathrm{nmol} / \mathrm{L}$ ); $70.4 \%$ and $97.8 \%$ of the cohort had serum $25(\mathrm{OH}) \mathrm{D}$ levels $<20$ and $<75 \mathrm{nmol} / \mathrm{L}$, respectively. Individuals with purely extrapulmonary TB $(11.4 \mathrm{nmol} / \mathrm{L}$; $95 \%$ CI 10.5 to $12.5 \mathrm{nmol} / \mathrm{L})$ and any extrapulmonary TB (11.4 nmol/L; 95\% CI 10.6 to $12.3 \mathrm{nmol} / \mathrm{L})$ had significantly lower serum $25(\mathrm{OH}) \mathrm{D}$ levels as compared with individuals with pulmonary TB only $(15.2 \mathrm{nmol} / \mathrm{L} ; 95 \% \mathrm{CI}$ 13.5 to $17.2 \mathrm{nmol} / \mathrm{L} ; \mathrm{p}<0.001$ and $\mathrm{p}<0.001$, respectively). Severe vitamin D deficiency (serum $25(\mathrm{OH}) \mathrm{D}<20 \mathrm{nmol} / \mathrm{L})^{16}$ was significantly more common in individuals with purely extrapulmonary TB $(74.7 \% ; \mathrm{p}=0.005)$ and individuals with any extrapulmonary involvement $(75.4 \% ; \mathrm{p}=0.001)$ than in subjects with purely pulmonary TB (60.9\%; see online supplementary figure S3). Among foreign-born non-white individuals who were UK-resident for $>1$ year, those who presented with purely extrapulmonary $(10.7 \mathrm{nmol} / \mathrm{L}$; $95 \%$ CI 9.8 to $11.6 \mathrm{nmol} / \mathrm{L})$ or any extrapulmonary TB $(10.7 \mathrm{nmol} / \mathrm{L}$; $95 \%$ CI 9.9 to $11.5 \mathrm{nmol} / \mathrm{L})$ had lower mean serum $25(\mathrm{OH}) \mathrm{D}$ levels than those with purely pulmonary TB $(12.7 \mathrm{nmol} / \mathrm{L} ; 95 \%$ CI 14.7 to $24.5 \mathrm{nmol} / \mathrm{L}$; $\mathrm{p}=0.030$ and $\mathrm{p}=0.020$, respectively).

On multivariable analysis (table 3), a doubling in serum 25 $(\mathrm{OH}) \mathrm{D}$ was associated with a reduced risk of purely extrapulmonary (OR $0.55,95 \%$ CI 0.41 to 0.73 ) and any extrapulmonary TB (OR 0.66 , 95\% CI 0.51 to 0.84 ). Additional factors independently associated with extrapulmonary disease included season of notification (highest in winter/spring when $25(\mathrm{OH}) \mathrm{D}$ levels are usually lowest ${ }^{16}{ }^{17}$ ), increasing age and, for the foreign-born, increasing time since arrival in the UK. Notably, while on univariable analysis non-white ethnicity was associated with extrapulmonary disease, on multivariable analysis, when taking serum $25(\mathrm{OH}) \mathrm{D}$ into account, the association with ethnicity disappeared. In a further sensitivity analysis, results remained quantitatively unchanged when analyses were restricted to those individuals who had had a vitamin D level measured within 30 days of commencing anti-tuberculous therapy (either before or after).

\section{DISCUSSION}

In two independent Northern hemisphere settings, clinical patterns of TB significantly and consistently differed by demographic and ethnic group in Northern latitudes. Collectively, 
Figure 1 Patterns of TB stratified by location of birth (local or foreign) and ethnic group (white vs non-white) for Birmingham and US Centers for Disease Control (CDC) datasets. ${ }^{1}$ Proportions are calculated on purely pulmonary and extrapulmonary cases only (ie, concurrent pulmonary and extrapulmonary cases are excluded for the purposes of this figure). ${ }^{2}$ For the Birmingham dataset, concurrent pulmonary and extrapulmonary case numbers (and proportions) were local-born white $72(4.1 \%)$, local-born non-white $136(7.2 \%)$ and

foreign-born non-white 547 (8.7\%).

${ }^{3}$ For the US CDC dataset, concurrent pulmonary and extrapulmonary case numbers (and proportions) were local-born white 3075 (5.6\%), local-born non-white $8939(9.1 \%)$ and foreign-born non-white 9009 (7.8\%).
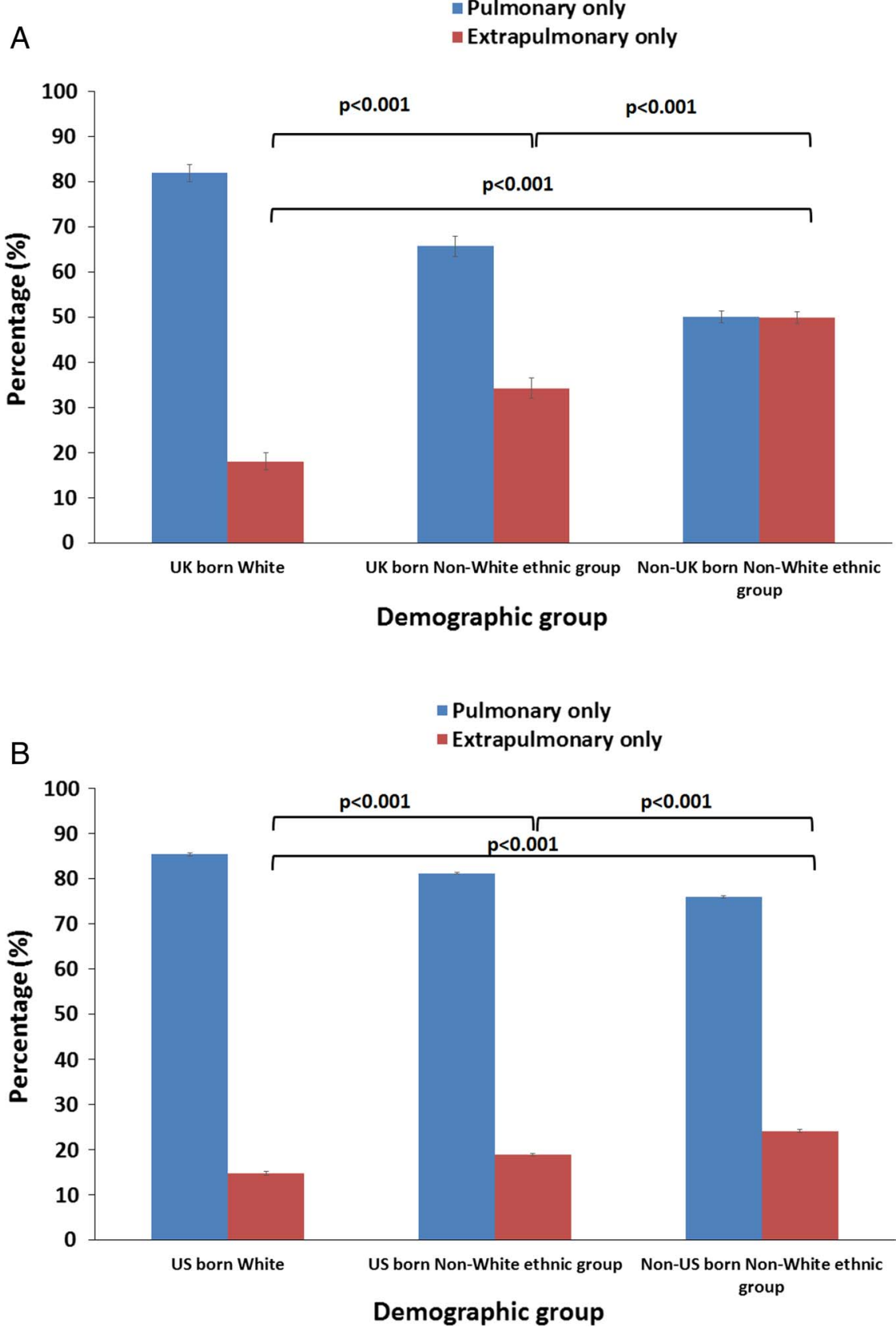

these findings suggest an environmental factor influencing clinical phenotype. The internationally and intranationally reproducible relationship of disease phenotype with foreign birth and non-white ethnicity potentially implicates vitamin $\mathrm{D}$ status. To directly test this possibility, we analysed serum $25(\mathrm{OH}) \mathrm{D}$ concentrations in an independent UK cohort and found that vitamin $\mathrm{D}$ deficiency, after adjusting for ethnicity and migration, was significantly associated with extrapulmonary TB. Our data potentially implicate an environmental factor (vitamin D) other than HIV-induced or iatrogenic immunosuppression influencing TB disease phenotype. Previous studies have found associations between sun exposure, ${ }^{18}$ seasonality ${ }^{19}{ }^{20}$ and TB incidence as well as between vitamin D deficiency and prevalence of latent ${ }^{21}$ and active TB. ${ }^{5}$ However, vitamin $\mathrm{D}$ deficiency has not hitherto been implicated in determining clinical phenotype. Despite vitamin D's pivotal role in antimycobacterial host defence ${ }^{22-26}$ and the augmentation of antimycobacterial immunity with vitamin D supplementation, ${ }^{27}$ the clinical effects of vitamin D deficiency in TB are unknown. We identify extrapulmonary TB as a potential clinical correlate of vitamin D deficiency.

The known associations between certain phylogenetic mycobacterial lineages and particular ethnic groups and disease sites might in theory have confounded our observations as the lineages of the infecting strains in our study populations were not known. However, in a subset of over 1000 patients with TB in the Birmingham cohort where the lineages of the infecting strains were known, non-white ethnicity was strongly and independently associated with extrapulmonary TB on multivariable analysis after taking mycobacterial lineage into account. ${ }^{12}$ In the current study, the fact that vitamin $\mathrm{D}$ deficiency was associated with extrapulmonary TB independently of nonary disease after taking vitamin D status into account) suggests that vitamin $\mathrm{D}$ deficiency may mediate the widely recognised association of non-white ethnicity with extrapulmonary dissemination. white ethnicity (which was not associated with extrapulmon- 
Table 2 Demographic, clinical and temporal variables associated with different patterns of TB for Birmingham dataset

\begin{tabular}{|c|c|c|c|c|c|c|c|c|c|}
\hline \multirow[b]{2}{*}{ Variable } & \multicolumn{4}{|l|}{ Whole cohort $(n=9389)^{*}$} & \multirow[b]{2}{*}{ Variable } & \multicolumn{4}{|c|}{ Non-white ethnic groups $(n=7478)^{*}$} \\
\hline & $\begin{array}{l}\text { Extrapulmonary TB only* } \\
(n=3799)\end{array}$ & $\begin{array}{l}\text { Unadjusted OR } \\
(95 \% \mathrm{Cl})\end{array}$ & $\begin{array}{l}\text { Adjusted ORt } \\
(95 \% \mathrm{CI})\end{array}$ & $p$ Value & & $\begin{array}{l}\text { Extrapulmonary TB only* } \\
(n=3460)\end{array}$ & $\begin{array}{l}\text { Unadjusted OR } \\
(95 \% \mathrm{Cl})\end{array}$ & $\begin{array}{l}\text { Adjusted OR } \\
(95 \% \mathrm{Cl})\end{array}$ & $\mathrm{p}$ Value \\
\hline Period & & & & & Period & & & & \\
\hline 1980-1984 & 568/1798 (31.6) & 1 & 1 & $<0.001$ & 1980-1984 & 487/1291 (37.7) & 1 & 1 & $<0.001$ \\
\hline 1985-1989 & 487/1345 (36.2) & $1.23(1.06$ to 1.43$)$ & 1.24 (1.06 to 1.46$)$ & & 1985-1989 & $426 / 1005(42.4)$ & 1.21 (1.03 to 1.44$)$ & 1.28 (1.08 to 1.53$)$ & \\
\hline 1990-1994 & 494/1471 (33.6) & $1.09(0.95$ to 1.27$)$ & 1.09 (0.94 to 1.28$)$ & & 1990-1994 & $431 / 1120(38.5)$ & 1.03 (0.88 to 1.22$)$ & $1.09(0.92$ to 1.3$)$ & \\
\hline 1995-1999 & $475 / 1242(38.2)$ & 1.34 (1.15 to 1.56$)$ & 1.28 (1.09 to 1.50$)$ & & 1995-1999 & $444 / 1001(44.4)$ & 1.32 (1.11 to 1.56$)$ & 1.41 (1.18 to 1.68$)$ & \\
\hline 2000-2004 & 755/1604 (47.1) & 1.93 (1.67 to 2.21$)$ & 1.85 (1.60 to 2.15$)$ & & 2000-2004 & 696/1348 (51.6) & $1.76(1.51$ to 2.06$)$ & 1.96 (1.67 to 2.31$)$ & \\
\hline 2005-2009 & $1020 / 1929(52.9)$ & 2.43 (2.13 to 2.78$)$ & 2.24 (1.94 to 2.59$)$ & & 2005-2009 & $976 / 1713(57.0)$ & 2.19 (1.89 to 2.53$)$ & 2.34 (2.01 to 2.74 ) & \\
\hline Season & & & & & Season & & & & \\
\hline Winter & 818/2118 (38.6) & 1 & 1 & 0.370 & Winter & 732/1661 (44.1) & 1 & 1 & 0.170 \\
\hline Spring & 956/2404 (39.8) & 1.05 (0.93 to 1.18$)$ & 0.99 (0.87 to 1.12$)$ & & Spring & 876/1908 (45.9) & 1.08 (0.94 to 1.23$)$ & 1.01 (0.88 to 1.16$)$ & \\
\hline Summer & 1062/2581 (41.2) & 1.11 (0.99 to 1.25$)$ & 1.04 (0.92 to 1.18$)$ & & Summer & 979/2075 (47.2) & 1.13 (1.00 to 1.29$)$ & 1.11 (0.97 to 1.27 ) & \\
\hline Autumn & $963 / 2286(42.1)$ & $1.16(1.03$ to 1.31$)$ & 1.09 (0.96 to 1.24$)$ & & Autumn & 873/1834 (47.6) & 1.15 (1.01 to 1.32$)$ & 1.14 (0.99 to 1.31$)$ & \\
\hline Age categories & & & & & Age categories & & & & \\
\hline$<16$ & 383/1167 (32.8) & 1 & 1 & $<0.001$ & $<16$ & 334/958 (34.9) & 1 & 1 & $<0.001$ \\
\hline $16-25$ & 652/1828 (35.7) & 1.13 (0.97 to 1.33$)$ & 0.80 (0.68 to 0.94$)$ & & $16-25$ & 634/1678 (37.8) & 1.13 (0.96 to 1.34$)$ & $0.86(0.72$ to 1.03$)$ & \\
\hline $26-35$ & $923 / 1840(50.2)$ & 2.06 (1.77 to 2.40$)$ & 1.34 (1.13 to 1.60$)$ & & $26-35$ & 889/1651 (53.8) & 2.18 (1.85 to 2.57$)$ & 1.42 (1.18 to 1.72$)$ & \\
\hline $36-45$ & $623 / 1240(50.2)$ & 2.07 (1.75 to 2.44$)$ & $1.49(1.23$ to 1.80$)$ & & $36-45$ & 579/999 (58.0) & $2.58(2.15$ to 3.09$)$ & 1.70 (1.37 to 2.10$)$ & \\
\hline $46-55$ & $468 / 1022(45.8)$ & 1.73 (1.45 to 2.06$)$ & $1.31(1.07$ to 1.60$)$ & & $46-55$ & $419 / 770(54.4)$ & $2.23(1.84$ to 2.71$)$ & 1.47 (1.17 to 1.85$)$ & \\
\hline Over 55 & 750/2292 (32.7) & $1.00(0.86$ to 1.16$)$ & 0.81 (0.68 to 0.98$)$ & & Over 55 & 605/1422 (42.5) & 1.38 (1.17 to 1.64$)$ & $0.83(0.67$ to 1.03$)$ & \\
\hline Gender & & & & & Gender & & & & \\
\hline Male & $1716 / 4831(35.5)$ & 1 & 1 & $<0.001$ & Male & $1541 / 3622(42.6)$ & 1 & 1 & $<0.001$ \\
\hline Female & 2083/4558 (45.7) & 1.53 (1.41 to 1.66$)$ & $1.43(1.31$ to 1.56$)$ & & Female & 1919/3856 (46.0) & 1.34 (1.22 to 1.47$)$ & 1.37 (1.24 to 1.50$)$ & \\
\hline Country of birth/ethnicity & & & & & $\begin{array}{l}\text { Country of birth/time since } \\
\text { entry }\end{array}$ & & & & \\
\hline UK-born white & $301 / 1663$ (18.1) & 1 & 1 & $<0.001$ & UK-born & 598/1741 (34.3) & 1 & 1 & $<0.001$ \\
\hline $\begin{array}{l}\text { UK-born Indian } \\
\text { Subcontinent }\end{array}$ & $421 / 1180(35.7)$ & 2.51 (2.11 to 2.98 ) & 2.29 (1.89 to 2.78$)$ & & Foreign-born/<1 year & 77/309 (24.9) & $0.63(0.48$ to 0.84$)$ & 0.61 (0.45 to 0.81 ) & \\
\hline UK-born Afro-Caribbean & 156/505 (30.9) & 2.02 (1.61 to 2.54$)$ & 1.81 (1.43 to 2.30$)$ & & Foreign-born/1-5 years & 931/1763 (52.8) & 2.14 (1.87 to 2.45$)$ & 1.87 (1.61 to 2.18$)$ & \\
\hline $\begin{array}{l}\text { UK-born Oriental/other } \\
\text { Asia }\end{array}$ & $3 / 13(23.1)$ & 1.36 (0.37 to 4.96$)$ & $1.10(0.30$ to 4.10$)$ & & Foreign-born/6-10 years & 405/733 (55.3) & 2.36 (1.98 to 2.81$)$ & 1.98 (1.63 to 2.42 ) & \\
\hline UK-born other & 18/43 (41.9) & 3.26 (1.76 to 6.05$)$ & 2.91 (1.54 to 5.50$)$ & & Foreign-born/>10 years & $1169 / 2340(50.0)$ & 1.91 (1.68 to 2.17$)$ & 1.64 (1.39 to 1.94$)$ & \\
\hline Foreign-born white & 38/248 (15.3) & 0.82 (0.57 to 1.18 ) & 0.94 (0.65 to 1.36$)$ & & $\begin{array}{l}\text { Foreign-born/time not } \\
\text { known }\end{array}$ & 280/592 (47.3) & $1.72(1.42$ to 2.07$)$ & 1.67 (1.34 to 2.07$)$ & \\
\hline $\begin{array}{l}\text { Foreign-born Indian } \\
\text { Subcontinent }\end{array}$ & 2308/4544 (50.8) & 4.67 (4.07 to 5.36$)$ & 4.10 (3.56 to 4.73 ) & & & & & & \\
\hline $\begin{array}{l}\text { Foreign-born } \\
\text { Afro-Caribbean }\end{array}$ & 390/836 (46.7) & 3.96 (3.29 to 4.76$)$ & 2.78 (2.29 to 3.38$)$ & & & & & & \\
\hline $\begin{array}{l}\text { Foreign-born Oriental/ } \\
\text { other Asia }\end{array}$ & 80/194 (41.2) & 3.18 (2.32 to 4.34$)$ & 2.78 (2.01 to 3.83 ) & & & & & & \\
\hline Foreign-born other & 84/163 (51.5) & 4.81 (3.45 to 6.70$)$ & 3.82 (2.72 to 5.37 ) & & & & & & \\
\hline
\end{tabular}


Table 2 Continued

\begin{tabular}{|c|c|c|c|c|c|c|c|c|c|}
\hline \multirow[b]{2}{*}{ Variable } & \multicolumn{4}{|l|}{ Whole cohort $(\mathrm{n}=9389)^{*}$} & \multirow[b]{2}{*}{ Variable } & \multicolumn{4}{|c|}{ Non-white ethnic groups $(n=7478)^{*}$} \\
\hline & $\begin{array}{l}\text { Extrapulmonary TB only* } \\
(\mathrm{n}=3799)\end{array}$ & $\begin{array}{l}\text { Unadjusted OR } \\
(95 \% \mathrm{Cl})\end{array}$ & $\begin{array}{l}\text { Adjusted ORt } \\
(95 \% \mathrm{Cl})\end{array}$ & $p$ Value & & $\begin{array}{l}\text { Extrapulmonary TB only* } \\
(n=3460)\end{array}$ & $\begin{array}{l}\text { Unadjusted OR } \\
(95 \% \mathrm{Cl})\end{array}$ & $\begin{array}{l}\text { Adjusted OR } \\
(95 \% \mathrm{Cl})\end{array}$ & p Value \\
\hline & & & & & Ethnicity§ & & & & \\
\hline & & & & & Indian Subcontinent & 2729/5724 (47.7) & 1 & 1 & $<0.001$ \\
\hline & & & & & Afro-Caribbean & $546 / 1341(40.7)$ & 0.75 (0.67 to 0.85$)$ & 0.69 (0.60 to 0.78$)$ & \\
\hline & & & & & $\begin{array}{l}\text { Oriental/Other Asia/ } \\
\text { Other }\end{array}$ & 185/413 (44.8) & $0.89(0.73$ to 1.09$)$ & 0.83 (0.67 to 1.02$)$ & \\
\hline Employment status & & & & & Employment status & & & & \\
\hline Unemployed & 167/401 (41.6) & 1 & & & Unemployed & $161 / 325(49.5)$ & 1 & & \\
\hline Retired & 106/292 (36.3) & $0.80(0.59$ to 1.09$)$ & & & Retired & $86 / 210(41.0)$ & $0.71(0.50$ to 1.00$)$ & & \\
\hline Employed/housewife & $819 / 1528$ (53.6) & $1.62(1.30$ to 2.02$)$ & & & Employed/housewife & 795/1393 (57.1) & 1.35 (1.06 to 1.72$)$ & & \\
\hline Student/child & $459 / 1365(33.6)$ & 0.71 (0.57 to 0.89$)$ & & & Student/child & $410 / 1149(35.7)$ & $0.57(0.44$ to 0.72$)$ & & \\
\hline Previous TB & & & & & Previous TB & & & & \\
\hline No & $2092 / 4321(48.4)$ & 1 & & & No & $1971 / 3700(53.3)$ & 1 & & \\
\hline Yes & $81 / 215(37.7)$ & $0.64(0.49$ to 0.85$)$ & & & Yes & $76 / 181(42.0)$ & 0.63 (0.47 to 0.86$)$ & & \\
\hline HIV status & & & & & HIV status & & & & \\
\hline Negative/unknown & $3793 / 9375(40.5)$ & 1 & 1 & 0.260 & Negative/unknown & $3454 / 7464(46.3)$ & 1 & 1 & 0.230 \\
\hline Positive & $6 / 14(42.9)$ & 1.10 (0.38 to 3.18$)$ & 0.54 (0.18 to 1.59$)$ & & Positive & $6 / 14(42.9)$ & $0.87(0.30$ to 2.51$)$ & 0.51 (0.17 to 1.52$)$ & \\
\hline Drug sensitivity & & & & & Drug sensitivity & & & & \\
\hline Fully sensitive & 585/1452 (40.3) & 1 & & & Fully sensitive & $566 / 1244(45.5)$ & 1 & & \\
\hline Monoresistant & $44 / 110(40.0)$ & $0.99(0.67$ to 1.47$)$ & & & Monoresistant & $44 / 100(44.0)$ & 0.94 (0.62 to 1.42$)$ & & \\
\hline Multidrug resistant & $7 / 26(26.9)$ & $0.55(0.23$ to 1.31$)$ & & & Multidrug resistant & $7 / 19$ (36.8) & $0.70(0.27$ to 1.79$)$ & & \\
\hline
\end{tabular}

*Comparison of extrapulmonary TB cases only versus pulmonary TB only (concurrent pulmonary-extrapulmonary cases excluded).

tModels mutually adjusted for year of notification, season of notification, age, gender, country of birth, ethnicity and HIV status.

$¥$ \Model mutually adjusted for year of notification, season of notification, age, gender, country of birth, time since arrival, ethnicity and HIV status.

$\S$ For the model restricted to non-white individuals, due to small numbers of individuals in the other category we collapsed together oriental/other Asian with the other category. 
Table 3 Demographic, clinical and temporal variables associated with different patterns of TB for the London and Leicester (vitamin D) cohort ( $n=462)$

\begin{tabular}{|c|c|c|c|c|c|c|c|c|c|}
\hline Variable & $\begin{array}{l}\text { Extrapulmonary } \\
\text { TB only* }(n=217)\end{array}$ & $\begin{array}{l}\text { Unadjusted OR } \\
(95 \% \mathrm{Cl})\end{array}$ & $\begin{array}{l}\text { Adjusted ORt } \\
(95 \% \mathrm{Cl})\end{array}$ & p Value & Variable & $\begin{array}{l}\text { Any extrapulmonary } \\
\text { involvement }(n=301)\end{array}$ & $\begin{array}{l}\text { Unadjusted OR } \\
(95 \% \mathrm{Cl})\end{array}$ & $\begin{array}{l}\text { Adjusted ORT } \\
(95 \% \mathrm{Cl})\end{array}$ & $\mathrm{p}$ Value \\
\hline Centre & & & & & Centre & & & & \\
\hline London & $63 / 102(61.8)$ & 1 & 1 & 0.050 & London & $82 / 121(67.8)$ & 1 & 1 & 0.140 \\
\hline Leicester & $154 / 276(55.8)$ & 0.78 (0.49 to 1.24$)$ & 0.42 (0.18 to 0.99$)$ & & Leicester & 219/341 (64.2) & 0.85 (0.55 to 1.33$)$ & $0.54(0.24$ to 1.21$)$ & \\
\hline Period of notification & & & & & Period of notification & & & & \\
\hline $2007-2009$ & $37 / 64(57.8)$ & 1 & 1 & 0.590 & 2007-2009 & $48 / 75(64.0)$ & 1 & 1 & 0.600 \\
\hline 2010-2012 & $180 / 314(57.3)$ & 0.98 (0.57 to 1.69$)$ & 1.31 (0.49 to 3.51$)$ & & 2010-2012 & $253 / 387(65.4)$ & 11.06 (0.63 to 1.78$)$ & $11.28(0.51$ to 3.24$)$ & \\
\hline Season & & & & & Season & & & & \\
\hline Winter & $51 / 82(62.3)$ & 1 & 1 & $<0.001$ & Winter & $72 / 103(69.9)$ & 1 & 1 & 0.003 \\
\hline Spring & $76 / 124(61.3)$ & 0.96 (0.54 to 1.71$)$ & 0.88 (0.44 to 1.75$)$ & & Spring & 104/152 (68.4) & 0.93 (0.54 to 1.60$)$ & 0.81 (0.43 to 1.52$)$ & \\
\hline Summer & $68 / 115(59.1)$ & 0.88 (0.49 to 1.57 ) & 1.11 (0.55 to 2.25 ) & & Summer & $94 / 141(66.7)$ & 0.86 (0.50 to 1.49$)$ & $1.00(0.52$ to 1.93$)$ & \\
\hline Autumn & $22 / 57(38.6)$ & 0.38 (0.19 to 0.77$)$ & 0.24 (0.10 to 0.55$)$ & & Autumn & $31 / 65(47.0)$ & 0.38 (0.20 to 0.72 ) & $0.30(0.14$ to 0.62$)$ & \\
\hline Age categories, $\mathrm{n}(\%)$ & & & & & Age categorical, n (\%) & & & & \\
\hline $16-25$ & $32 / 79(40.5)$ & 1 & 1 & 0.005 & $16-25$ & $54 / 101(53.5)$ & 1 & 1 & 0.040 \\
\hline $26-35$ & $64 / 115(55.7)$ & 1.84 (1.03 to 3.29$)$ & 1.90 (0.95 to 3.78$)$ & & $26-35$ & $93 / 144(64.6)$ & 1.59 (0.94 to 2.67$)$ & 1.53 (0.83 to 2.81$)$ & \\
\hline $36-45$ & $54 / 77(70.1)$ & 3.44 (1.77 to 6.69$)$ & 4.28 (1.87 to 9.81$)$ & & $36-45$ & $64 / 87(73.6)$ & 2.42 (1.31 to 4.49$)$ & 2.81 (1.32 to 5.99$)$ & \\
\hline $46-55$ & $31 / 50(62.0)$ & 2.40 (1.16 to 4.96$)$ & 4.08 (1.59 to 10.47$)$ & & $46-55$ & $44 / 63(69.8)$ & 2.02 (1.04 to 3.92$)$ & 2.64 (1.14 to 6.08$)$ & \\
\hline Over 55 & $36 / 57(63.2)$ & 2.52 (1.25 to 5.08$)$ & 4.14 (1.56 to 11.02$)$ & & Over 55 & $46 / 67(68.7)$ & 1.91 (0.99 to 3.64$)$ & 3.06 (1.26 to 7.43$)$ & \\
\hline Gender & & & & & Gender & & & & \\
\hline Male & $110 / 208(52.9)$ & 1 & 1 & 0.063 & Male & 165/263 (62.7) & 1 & 1 & 0.160 \\
\hline Female & $107 / 170(62.9)$ & 1.51 (1.00 to 2.29$)$ & 1.62 (0.97 to 2.69$)$ & & Female & $136 / 199(68.3)$ & 1.28 (0.87 to 1.89$)$ & $1.40(0.88$ to 2.24$)$ & \\
\hline Country of birth/time since entry & & & & & Country of birth/time since entry & & & & \\
\hline UK-born & $21 / 62(33.9)$ & 1 & 1 & 0.003 & UK-born & $24 / 65(36.9)$ & 1 & 1 & 0.001 \\
\hline Foreign-born/<1 year & $4 / 13(30.8)$ & $0.87(0.24$ to 3.15$)$ & 0.88 (0.19 to 4.13$)$ & & Foreign-born/<1 year & $5 / 14(35.7)$ & 0.95 (0.28 to 3.16$)$ & 0.68 (0.15 to 2.95$)$ & \\
\hline $\begin{array}{l}\text { Foreign-born/ } \\
1-5 \text { years }\end{array}$ & $59 / 101(58.4)$ & $2.74(1.42$ to 5.30$)$ & 2.71 (1.19 to 6.14$)$ & & Foreign-born/1-5 years & $99 / 141(70.2)$ & 4.03 (2.17 to 7.48$)$ & 3.75 (1.77 to 7.95$)$ & \\
\hline $\begin{array}{l}\text { Foreign-born/ } \\
6-10 \text { years }\end{array}$ & $50 / 71(66.3)$ & 4.65 (2.23 to 9.67$)$ & 4.76 (1.95 to 11.64$)$ & & Foreign-born/6-10 years & $58 / 79(73.4)$ & 4.72 (2.32 to 9.59$)$ & $4.07(1.75$ to 9.45$)$ & \\
\hline Foreign-born $/>10$ years & $73 / 107(68.2)$ & 4.19 (2.16 to 8.15$)$ & 2.42 (1.04 to 5.66$)$ & & Foreign-born $/>10$ years & 99/133 (74.4) & 4.97 (2.63 to 9.40$)$ & 2.84 (1.28 to 6.30$)$ & \\
\hline Foreign-born/time not known & $3 / 11(27.3)$ & 0.73 (0.18 to 3.05$)$ & 0.51 (0.11 to 2.90$)$ & & Foreign-born/time not known & $8 / 16(50.0)$ & 1.71 (0.57 to 5.14$)$ & $1.53(0.43$ to 5.46$)$ & \\
\hline Ethnicity & & & & & Ethnicity & & & & \\
\hline White & $18 / 51(35.3)$ & 1 & 1 & 0.650 & White & 19/52 (36.5) & 1 & 1 & 0.170 \\
\hline Indian Subcontinent & $136 / 224(60.7)$ & 2.83 (1.50 to 5.34$)$ & 1.53 (0.64 to 3.67 ) & & Indian Subcontinent & $188 / 276(68.1)$ & 3.71 (2.00 to 6.89$)$ & 2.21 (0.97 to 5.02$)$ & \\
\hline Afro-Caribbean & $33 / 52(63.5)$ & 3.18 (1.42 to 7.12$)$ & 1.43 (0.51 to 4.02$)$ & & Afro-Caribbean & 46/65 (70.8) & 4.20 (1.93 to 9.15$)$ & $1.99(0.76$ to 5.22$)$ & \\
\hline Oriental/other Asia/other & $30 / 51(58.8)$ & 2.62 (1.18 to 5.83$)$ & 1.94 (0.69 to 5.39 ) & & Oriental/other Asia/other & $48 / 69(69.6)$ & 3.97 (1.85 to 8.51$)$ & 2.88 (1.11 to 7.45$)$ & \\
\hline Vitamin D status & & & & & Vitamin D & & & & \\
\hline $25(\mathrm{OH}) \mathrm{D}$ level $\left(\log _{2} \mathrm{nmol} / \mathrm{L}\right) \neq$ & & 0.68 (0.55 to 0.83$)$ & 0.55 (0.41 to 0.73 ) & $<0.001$ & Vitamin D level $\left(\log _{2} \mathrm{nmol} / \mathrm{L}\right)$ & & 0.68 (0.56 to 0.82 ) & $0.66(0.51$ to 0.84$)$ & 0.001 \\
\hline HIV status & & & & & HIV status & & & & \\
\hline Negative & 198/354 (55.9) & 1 & 1 & 0.350 & Negative & $274 / 430(63.7)$ & 1 & 1 & 0.520 \\
\hline Positive & $5 / 7(71.4)$ & $1.97(0.38$ to 10.29$)$ & $2.59(0.36$ to 18.69$)$ & & Positive & $6 / 8(75.0)$ & $1.71(0.34$ to 8.56$)$ & $1.87(0.28$ to 12.74$)$ & \\
\hline
\end{tabular}

*Comparison of extrapulmonary TB cases-only versus pulmonary TB-only (concurrent pulmonary-extrapulmonary cases excluded).

†Models mutually adjusted for period of notification, season of notification, age, gender, country of birth/time since entry, ethnicity, 25(OH)D level and HIV status.

$\neq$ Refers to the OR associated with an increase in continuous log-transformed 25(OH)D levels by $\log _{2}$ (which corresponds to a doubling in 25(OH)D levels). 
Although men are more likely to present with TB per se, we found that extrapulmonary $\mathrm{TB}$ was associated with female gender, as previously observed. ${ }^{2}{ }^{11}$ Vitamin D deficiency is more common in women ${ }^{17}$ and, interestingly, the association of female gender with extrapulmonary TB disappeared after taking vitamin D status into account on multivariable analysis.

Although seasonality of TB incidence has previously been reported, ${ }^{19}$ this is the first study to assess TB seasonality in a population with known $25(\mathrm{OH}) \mathrm{D}$ status, enabling us to independently assess the influence of these two factors on disease phenotype. The proportion of extrapulmonary to pulmonary TB was highly seasonal, being highest in winter and spring (when 25(OH)D status is lowest in Northern Hemisphere residents) and lowest in the autumn (when $25(\mathrm{OH}) \mathrm{D}$ status is highest). However, after controlling for 25(OH)D status, extrapulmonary $\mathrm{TB}$ incidence remained independently associated with seasonality, suggesting that an additional, as yet undetermined, seasonal factor may influence clinical phenotype.

The intermediate prevalence of extrapulmonary TB in localborn non-whites (between UK-born whites and foreign-born non-whites) is consistent with a role for vitamin $\mathrm{D}$ deficiency since UK-born non-whites have intermediate levels of 25(OH)D when compared with UK-born whites and foreign-born nonwhites. ${ }^{28}$ Interestingly, the increasing prevalence of extrapulmonary TB in the USA, especially in non-white individuals, corresponds to the increasing prevalence of vitamin D deficiency in the USA over time which is also most marked in non-white individuals. ${ }^{29}$ Such changes might also explain the temporal trend in Birmingham, although there may be increasing ascertainment with wider use of cross-sectional radiology.

The large sample size, independent northern latitude settings and multiple diverse ethnic groups in this study suggest that our findings are generalisable. Moreover, the size of effect for the association between vitamin $\mathrm{D}$ deficiency and extrapulmonary disease is not inconsequential, being higher than, or in line with, ORs associated with pathogen ${ }^{9}$ and host genetic ${ }^{6}$ factors predisposing to extrapulmonary TB.

How vitamin D deficiency preferentially favours development of extrapulmonary TB is unclear and may depend on whether haematogenous spread to extrapulmonary sites occurs after primary infection. If following initial infection, Mycobacterium tuberculosis is contained within the lungs, then vitamin D deficiency may cause T-cell immunosuppression or upregulated matrix metalloproteinase activity promoting basement membrane penetration, ${ }^{30}$ resulting in impaired bacillary containment predisposing to extrathoracic dissemination and seeding. This would then increase the likelihood of extrapulmonary disease upon subsequent reactivation. Alternatively, if bacilli routinely spread haematogenously after initial pulmonary infection and are then contained by host responses in peripheral extrapulmonary sites as well as in the lung, the mechanisms of peripheral containment may be more vitamin D-dependent than those in the lung. Regardless of which model is correct, our patientbased data support a role for vitamin D in bacillary containment, suggesting that the potent downstream vitamin D-dependent antimycobacterial macrophage effector mechanisms elucidated in vitro might also mediate mycobacterial containment in vivo. 222526

Our work has several limitations. Data were obtained from surveillance systems limiting our analysis to routinely collected variables. HIV status was incompletely recorded in the surveillance datasets; ${ }^{2}$ however, in the separate UK cohort where 25 $(\mathrm{OH}) \mathrm{D}$ was measured, HIV status was known for most patients. Given the US CDC aggregate data, regression modelling was univariable rather than multivariable. In the vitamin $\mathrm{D}$ cohort not all patients had vitamin D levels checked or checked in the eligible time period and it is possible that physicians only selected specific patients for testing meaning that we could not completely exclude the possibility of selection bias. We did not have data on possible use of vitamin D supplements. Also, it is possible that serum $25(\mathrm{OH}) \mathrm{D}$ concentrations may have been affected by anti-tuberculous treatment in those individuals who had already commenced treatment but any such effect was mitigated by including only patients whose levels were measured within 30 days of treatment initiation. In any event, both these latter factors would have affected all TB phenotypes equally, not specifically extrapulmonary TB. It is possible that the extrapulmonary phenotype was related to some other unmeasured factor (such as socioeconomic or nutritional status), which was in turn correlated both with ethnicity and with vitamin D status. Furthermore, it is possible, although unproven, that patients with extrapulmonary $\mathrm{TB}$ might behave differently to patients with pulmonary $\mathrm{TB}$ (eg, spending more time indoors) consequently resulting in lower vitamin D levels.

Our classification of TB disease was based on exclusively pulmonary or extrapulmonary involvement. Since extrapulmonary disease is more likely to be culture-negative, it might theoretically have been clinically overdiagnosed in certain demographic groups. However, this is unlikely as our findings were based on complete surveillance datasets and were unaffected by changes in classification of extrapulmonary TB (where extrapulmonary was defined as pulmonary plus extrapulmonary) and by limiting analysis to culture-positive cases only.

While vitamin D deficiency appears to be a risk factor for extrapulmonary TB, our findings do not confirm causality. It is theoretically possible that deficiency is a consequence of unrelated immunological changes that predispose to extrapulmonary TB or instead caused by an extrapulmonary disease phenotype or dissemination (ie, reverse causality). If vitamin D deficiency does play a causal role, the implications for international public health, particularly migrant health, as well as for mechanisms of in vivo containment of $M$ tuberculosis could be considerable.

\section{Author affiliations}

${ }^{1}$ Department of Infection, Immunity and Inflammation, University of Leicester, Leicester, UK

${ }^{2}$ Tuberculosis Research Centre, National Heart and Lung Institute, Imperial College London, London, UK

${ }^{3}$ Department of Infectious Disease Epidemiology, Imperial College London, London, UK ${ }^{4}$ Department of Infection and Tropical Medicine, University Hospitals Leicester NHS Trust, Leicester, UK

${ }^{5}$ Department of Infection and Tropical Medicine, Heart of England NHS Foundation Trust, Bordesley Green East, Birmingham, UK

${ }^{6}$ Department of Respiratory Medicine, Institute for Lung Health, University Hospitals Leicester NHS Trust, Leicester, UK

${ }_{7}^{7}$ Centre for Primary Care and Public Health, Barts and The London School of Medicine and Dentistry, Queen Mary University of London, London, UK

${ }^{8}$ Tuberculosis Service, Department of Chest and Allergy Clinic, St. Mary's Hospital, Imperial College Healthcare NHS Trust, London, UK

Contributors AL, MP and SS conceived of the idea for the study. JI, MD, MW and GW collected the clinical data as part of routine care. LG extracted data for the London cohort. MP undertook the data analysis. MP and AL wrote the first draft of the manuscript with subsequent revisions made by all other coauthors. All coauthors had sight of the submitted paper. AL is guarantor for the paper.

Funding MP is an NIHR Academic Clinical Lecturer in Infectious Diseases. His PhD was funded by a Medical Research Council Capacity Building Studentship. AL is a Wellcome Senior Research Fellow in Clinical Science and NIHR Senior Investigator. This work was supported by the NIHR Health Protection Research Unit in Respiratory Infections, Imperial College London. The funding bodies played no role in data collection, analysis or interpretation. They were not involved in the decision to submit the paper for publication. None of the authors have been paid to write this article by a pharmaceutical company or other agency. The corresponding author had 
full access to all the data in the study and had final responsibility for the decision to submit for publication.

Competing interests $\mathrm{AL}$ is Non-Executive Director of a nutraceutical company several of whose products contain vitamin D. MP, JI, SS, LG, DC, GW, MW, ARM, $\mathrm{OMK}$ and MD declare that they have no conflict of interest.

Provenance and peer review Not commissioned; externally peer reviewed.

\section{REFERENCES}

1 Peto HM, Pratt RH, Harrington TA, et al. Epidemiology of extrapulmonary tuberculosis in the United States, 1993-2006. Clin Infect Dis 2009;49:1350-7.

2 Kruijshaar ME, Abubakar I. Increase in extrapulmonary tuberculosis in England and Wales 1999-2006. Thorax 2009;64:1090-5.

3 Yang $Z$, Kong $Y$, Wilson $F$, et al. Identification of risk factors for extrapulmonary tuberculosis. Clin Infect Dis 2004;38:199-205.

4 Keane J, Gershon S, Wise RP, et al. Tuberculosis associated with infliximab, a tumor necrosis factor $\alpha$-neutralizing agent. N Engl J Med 2001;345:1098-104.

5 Wilkinson RJ, Llewelyn M, Toossi Z, et al. Influence of vitamin D deficiency and vitamin $D$ receptor polymorphisms on tuberculosis among Gujarati Asians in west London: a case-control study. Lancet 2000;355:618-21.

6 Motsinger-Reif A, Antas P, Oki N, et al. Polymorphisms in IL-1beta, vitamin D receptor Fok1, and Toll-like receptor 2 are associated with extrapulmonary tuberculosis. BMC Med Genet 2010;11:37.

7 Wilkinson RJ, Patel P, Llewelyn $M$, et al. Influence of polymorphism in the genes for the Interleukin (IL)-1 receptor antagonist and IL-1 $\hat{\mid}^{2}$ on tuberculosis. J Exp Med 1999;189:1863-74.

8 Fernando SL, Saunders BM, Sluyter R, et al. A polymorphism in the P2X7 gene increases susceptibility to extrapulmonary tuberculosis. Am J Respir Crit Care Med 2007; 175:360-6.

9 Click ES, Moonan PK, Winston CA, et al. Relationship between Mycobacterium tuberculosis phylogenetic lineage and clinical site of tuberculosis. Clin Infect Dis 2012;54:211-19.

10 Lari N, Rindi L, Cristofani R, et al. Association of Mycobacterium tuberculosis complex isolates of Bovis and Central Asian (CAS) genotypic lineages with extrapulmonary disease. Clin Microbiol Infect 2009;15:538-43.

11 Forssbohm M, Zwahlen M, Loddenkemper R, et al. Demographic characteristics of patients with extrapulmonary tuberculosis in Germany. Eur Respir J 2008;31:99-105.

12 Pareek M, Evans JT, Innes J, et al. Ethnicity and mycobacterial lineage as determinants of tuberculosis disease phenotype. Thorax 2013;68:221-9 (in press).

13 Office for National Statistics. Annual Population Survey: Population by country of birth and nationality October 2009 to September 2010. London: Office for National Statistics, 2010
14 Health Protection Agency. Three-year average tuberculosis case reports and rates by Primary Care Trust, England, 2006-2008. London: Health Protection Agency, 2009.

15 Centres for Disease Control. Online Tuberculosis Information System, National Tuberculosis Surveillance System, United States, 1993-2009. CDC, 2011.

16 Holick MF. Vitamin D Deficiency. N Engl J Med 2007;357:266-81.

17 Hyppönen E, Power C. Hypovitaminosis D in British adults at age $45 \mathrm{y}$ : nationwide cohort study of dietary and lifestyle predictors. Am J Clin Nutr 2007;85:860-8.

18 Perez-Trallero E, Cilla G, Garcia-Zamalloa A, et al. Vitamin D and tuberculosis incidence in Spain. Am J Respir Crit Care Med 2008;177:798.

19 Martineau A, Nhamoyebonde S, Oni T, et al. Reciprocal seasonal variation in vitamin D status and tuberculosis notifications in Cape Town, South Africa. PNAS 2011;108:19013-17.

20 Willis MD, Winston CA, Heilig CM, et al. Seasonality of Tuberculosis in the United States, 1993-2008. Clin Infect Dis 2012;54:1553-60.

21 Gibney KB, MacGregor L, Leder K, et al. Vitamin D deficiency is associated with tuberculosis and latent tuberculosis infection in immigrants from Sub-Saharan Africa. Clin Infect Dis 2008;46:443-6.

22 Liu PT, Stenger S, Li H, et al. Toll-like receptor triggering of a vitamin D-mediated human antimicrobial response. Science 2006;311:1770-3.

23 Crowle AJ, Elkins N. Relative permissiveness of macrophages from black and white people for virulent tubercle bacilli. Infect Immun 1990;58:632-8.

24 Rook GA, Steele J, Fraher L, et al. Vitamin D3, gamma interferon, and control of proliferation of Mycobacterium tuberculosis by human monocytes. Immunology 1986;57:159-63.

25 Fabri M, Stenger S, Shin DM, et al. Vitamin D is required for IFN-gamma-mediated antimicrobial activity of human macrophages. Sci Trans/ Med 2011;12:104.

26 Martineau AR, Wilkinson KA, Newton SM, et al. IFN- $\boldsymbol{\gamma}$ - and TNF-independent Vitamin D-inducible human suppression of mycobacteria: the role of Cathelicidin LL-37. J Immunol 2007;178:7190-8.

27 Martineau AR, Wilkinson RJ, Wilkinson KA, et al. A single dose of Vitamin D enhances immunity to mycobacteria. Am J Respir Crit Care Med 2007;176: 208-13.

28 Stephens WP, Klimiuk PS, Warrington S, et al. Observations on the natural history of vitamin $D$ deficiency amongst Asian immigrants. Q J Med 1982;202:171-88.

29 Looker AC, Pfeiffer CM, Lacher DA, et al. Serum 25-hydroxyvitamin D status of the US population: 1988-1994 compared with 2000-2004. Am J Clin Nutr 2008;88:1519-27.

30 Coussens AK, Timms PM, Venton TR, et al. 1 $\alpha, 25$-dihydroxyvitamin $D_{3}$ inhibits matrix metalloproteinases induced by Mycobacterium tuberculosis infection. Immunology 2009;127:539-48. 